\title{
Susceptibility of Sigmodon hispidus
}

by Krishnan Kolappaswamy, DVM, PhD, DACLAM

\section{SCIENTIFIC NAME}

Sigmodon hispidus

TAXONOMY

PHYLUM: Chordata

CLASS: Mammalia

ORDER: Rodentia

FAMILY: Cricetidae

\section{Physical description}

Cotton rats are native to the southern US, Central America, Columbia and Venezuela. They thrive in dense grass cover and marshy fields, where they feed on grains, insects, small birds and eggs. Adult cotton rats weigh around $100-250 \mathrm{~g}$ and are stocky and robust in stature.

\section{Reproduction and husbandry}

Cotton rats in the wild are solitary in nature, which makes them very territorial and aggressive. In the wild, the males are generally more dominant than females, and the only time they come together is for mating. In a laboratory animal facility setting, often the females are aggressive towards the males, and care should be taken when females are introduced into a male's cage for breeding. Female cotton rats are spontaneous ovulators, and breeding is not seasonal. The gestation period is usually $27-28 \mathrm{~d}$, and the average litter consists of five pups. Postpartum estrus occurs within $12 \mathrm{~h}$ of parturition ${ }^{1}$. Pups are semiprecocious at birth, and weaning normally occurs by 3 weeks of age.

Cotton rats are highly excitable and can escape easily from an open cage. Personnel should remain calm and be careful when moving them from one cage to another. Owing to their aggressive nature, personnel should wear thick, protective gloves when handling cotton rats. Cotton rats often become acclimated to personnel who handle them routinely.

\section{Research résumé}

Cotton rats serve as excellent, alternative models for pathogens that do not infect conventional rat and mouse models ${ }^{1}$. Wild cotton rats were used in polio research in 1937. After World War II, they were used in development of the typhus vaccine and in dental caries research. Cotton rats have been used to model many different respiratory infections and their associated immunogenicity ${ }^{2,3}$. These include measles ${ }^{3,4}$, adenovirus $s^{3,5}$, respiratory syncytial virus $s^{3,6,7}$, human influenza virus ${ }^{3,6,8}$, metapneumovirus ${ }^{3,6}$, human rhinovirus ${ }^{3}$, parainfluenza virus ${ }^{2,3}$, tuberculosis ${ }^{9}$ and nasal colonization of Staphylococcus aureus ${ }^{8,10}$.

Cotton rats have also been used in studies of herpes simplex virus, Venezuelan equine encephalitis and human immunodeficiency virus $^{2}$. In addition to bacterial and viral infections, cotton rats have been used to study fungi such as Microsporum and Trichophyton and parasites including Brugia, Coccidia, Dipetalonema, Echinococcus, Fasciola, Leishmania and Litomosoides ${ }^{2}$.

Cotton rat cell lines and reagents, such as monoclonal antibodies and cytokines, are now available to facilitate studies of vaccine and antiviral therapies ${ }^{2,11}$.

1. Curlee, J.F. \& Cooper, D.M. in The Laboratory Rabbit, Guinea Pig, Hamster, and Other Rodents (eds. Suckow, M.A., Stevens, K.A. \& Wilson, R.P.) 1105-1111 (Elsevier, Waltham, MA, 2012).

2. Niewiesk, S. \& Prince, G. Diversifying animal models: the use of hispid cotton rats (Sigmodon hispidus) in infectious diseases. Lab. Anim. 36, 357-372 (2002).

3. Blanco, J.C., Boukhvalova, M.S., Perez, D.R., Vogel, S.N. \& Kajon, A. Modeling human respiratory viral infections in the cotton rat (Sigmodon hispidus). J. Antivir. Antiretrovir. 6, 40-42 (2014).

4. Niewiesk, S. Current animal models: cotton rat animal model. Curr. Top. Microbiol. Immunol. 330, 89-110 (2009).

5. Pacini, D.L., Dubovi, E.J. \& Clyde, W.A. A new animal model for human respiratory tract disease due to adenovirus. J. Infect. Dis. 150, 92-97 (1984).

6. Boukhvalova, M.S., Prince, G.A. \& Blanco, J.C. The cotton rat model of respiratory viral infections. Biologicals 37, 152-159 (2009).

7. Prince, G.A., Jenson, A.B., Horswood, R.L., Camargo, E. \& Chanock, R.M. The pathogenesis of respiratory syncytial virus infection in cotton rats. Am. J. Pathol. 93, 771-791 (1978).

8. Braun, L.E. et al. Co-infection of the cotton rat (Sigmodon hispidus) with Staphylococcus aureus and influenza A virus results in synergistic disease. Microb. Pathog. 43, 208-216 (2007).

9. Elwood, R.L. et al. The American cotton rat: a novel model for pulmonary tuberculosis. Tuberculosis (Edinb). 87, 145-154 (2007).

10. Kokai-Kun, J.F. The cotton rat as a model for Staphylococcus aureus nasal colonization in humans: cotton rat $S$. aureus nasal colonization model. Methods Mol. Biol. 431, 241-254 (2008).

11. Blanco, J.C. et al. The cotton rat: an underutilized animal model for human infectious diseases can now be exploited using specific reagents to cytokines, chemokines, and interferons. J. Interferon Cytokine Res. 24, 21-28 (2004). 